\title{
IMPLEMENTASI PERATURAN MENTERI KESEHATAN RI NOMOR 2581/MENKES/PER/XII/2011 TENTANG PETUNJUK TEKNIS PELAYANAN KESEHATAN DASAR JAMINAN KESEHATAN MASYARAKAT
}

\section{IMPLEMENTATION OF THE REGULATION OF THE MINISTER OF HEALTH RI NUMBER 2581 / MENKES / PER / XII / 2011 CONCERNING TECHNICAL HEALTH INSURANCE SERVICES BASIC HEALTH OF COMMUNITY HEALTH}

\author{
Lusi Amara Fernanda ${ }^{1}$, Linayati Lestari ${ }^{2}$ \\ ${ }^{1}$ (Prodi Ilmu Pemerintahan, Fakulta Ilmu Sosial \& Ilmu Politik, Universitas Riau Kepulauan, Indonesia) \\ ${ }^{2}$ (Prodi Ilmu Pemerintahan, Fakultas Ilmu Sosial \& Ilmu Politik, Universitas Riau Kepulauan, Indonesia) \\ Ilusiamaraf@gmailcom, ${ }^{2}$ linayatilestari@yahoo.com
}

\begin{abstract}
Abstrak
Kesehatan masyarakat merupakan upaya untuk memenuhi salah satu hak rakyat yang sangat fundamental. Kesehatan masyarakat juga sekaligus sebagai investasi pembangunan nasional, dengan demikian kesehatan merupakan bagian dari pembangunan nasional. Upaya mewujudkan hak fundamental tersebut adalah kewajiban dari pemerintah untuk menyelenggarakan pelayanan kesehatan yang merata, adil dan terjangkau bagi seluruh lapisan masyarakat. Untuk menjamin akses penduduk miskin terhadap pelayanan kesehatan, Pemerintah telah menyelenggarakan program Jaminan Kesehatan Masyarakat (Jamkesmas).Jamkesmas diharapkan sebagai akses terhadap pelayanan kesehatan bagi masyarakat miskin dan tidak mampu dapat diatasi sesuai dengan peraturan menteri kesehatan RI Nomor 2581/menkes/PER/XII/2011 tentang petunjuk teknis pelayanan kesehatan dasar jaminan kesehatan masyarakat di Puskesmas sekupang kota Batam tahun 2013.Penelitian yang digunakan adalah Kualitatif. Penelitian kualitatif menekankan pada pemahaman megenai masalah-masalah dalam kehidupan sosial berdasarkan kondisi realitas, kompleks, dan rinci. Penelitian kualitatif tentang riset yang bersifat deskriptif dan cenderung menggunakan analisis. Proses dan makna (perspektif subyek) lebih ditonjolkan dalam penelitian kualitatif. Sumber data didapatkan berdasarkan wawancara, fakta dilapangan dan dokumentasi yang ada di Puskesmas Sekupang Kota Batam.Dalam pelaksanaan pelayanan kesehatan terhadap Jaminan Kesehatan Masyarakat di Kota Batam masih mengalami berbagai hambatan, baik hambatan dari dalam yaitu pihak petugas Puskesmas Sekupang maupun dari luar yaitu masyarakat di wilayah Puskesmas Sekupang. Untuk mengoptimalkan pelayanan jaminan kesehatan masyarakat khususnya di Puskesmas Sekupang Kota Batam maka pelayanan jaminan kesehatan masyarakat harus berjalan secara efektif dan efisien, butuh usaha untuk menghasilkan pelayanan jaminan kesehatan yang optimal sebagai akibat dari efisiensi dan efektivitas pengelolaan pelayanan kesehatan tersebut, sehingga target penerima pelayanan kesehatan dapat terealisasi.Secara umum Implementasi Peraturan Menteri Kesehatan RI Nomor 2581/menkes/PER/XII/2011 tentang petunjuk teknis pelayanan kesehatan dasar jaminan kesehatan masyarakat harus diarahkan guna pencapaian kondisi yang kondusif bagi seluruh aspek kehidupan masyarakat Kota Batam dan khususnya dalam kawasan Puskesmas Sekupang tentang pelayanan jaminan kesehatan masyarakat perlu disesuaikan dan diatur sesuai dengan perkembangannya, dan kebutuhan masyarakat.
\end{abstract}

Kata kunci: Implementasi Kebijakan, Peraturan Menteri, Pelayanan,Jaminan Kesehatan Masyarakat.

\begin{abstract}
Public health is an effort to fulfill one of the fundamental rights of the people. Public health is also at the same time an investment of national development, thus health is part of national development. The effort to realize these fundamental rights is the obligation of the government to provide equitable, fair and affordable health services for all levels of society. To ensure access of the poor to health services, the Government has organized a Public Health Insurance (Jamkesmas) program.Jamkesmas is expected as access to health services for the poor and incapable can be addressed in accordance with the regulation of the Minister of Health No. 2581 / Menkes / PER / XII / 2011 on technical guidance of basic health care health service at Puskesmas sekupang city of Batam in 2013.The research used is qualitative. Qualitative research emphasizes the understanding of problems in social life based on reality, complex, and detailed conditions. Qualitative research on research that is descriptive and tend to use analysis. Process and meaning (subject perspective) are more highlighted in qualitative research. Sources of data obtained based on interviews, facts in the field and documentation that existed in Puskesmas Sekupang Batam City.In the implementation of health services to the Public Health
\end{abstract}


Insurance in Batam City is still experiencing a variety of barriers, both inhibition from the public health center staff Sekupang and from outside the community in Sekupang Puskesmas. To optimize public health insurance services, especially in Sekupang Health Center Batam, public health insurance services must run effectively and efficiently, it takes effort to produce optimal health insurance services as a result of the efficiency and effectiveness of health service management, so that the target of health service recipients can Realized.In general, Implementation of Regulation of Minister of Health Number 2581 / menkes / PER / XII / 2011 on technical guidance of basic health service of public health guarantee must be directed to achieve conducive condition for all aspect of life of Batam City and especially in Sekupang Public Health Center area about health insurance service Society needs to be adjusted and managed in accordance with its development, and community needs.

Keywords: Policy Implementation, Ministerial Regulation, Health Service, and Public Health Insurance

\section{PENDAHULUAN}

Kesehatan masyarakat merupakan upaya untuk memenuhi salah satu hak rakyat yang sangat fundamental. Kesehatan masyarakat juga sekaligus sebagai investasi pembangunan nasional, dengan demikian kesehatan merupakan bagian dari pembangunan nasional. Dalam kaitan ini pembangunan nasional perlu berwawasan kesehatan. Diharapkan setiap program pembangunan nasional yang terkait dengan kesehatan, dapat memberikan kontribusi yang positif terhadap tercapainya nilai-nilai dasar kesehatan.

Untuk terselenggaranya pembangunan nasional berwawasan kesehatan, perlu dilaksanakan kegiatan advokasi, sosialisasi, orientasi, kampanye dan pelatihan, sehingga semua pelaku pembangunan nasionalmemahami dan mampu melaksanakanpembangunan nasioanl berwawasan kesehatan. Puskesmas dan jaringannya sebagai sarana pelayanan kesehatan terdepan mempunyai tugas menjangkau masyarakat, sebaliknya puskesmas dan jaringannya diharapkan dapat dijangkau oleh masyarakat di wilayah kerja sehingga puskesmas dan jaringannya bertanggung jawab menyelenggarakan pelayanan kesehatan di wilayah kerja secara proaktif dan responsive, pemerintah memiliki peranan untuk melaksanakan fungsi pelayanan dan pengaturan warga negara. Untuk mengimplementasikan fungsi tersebut pemerintah melakukan aktivitas pelayanan, pengaturan, pembinaan, koordinasi dan pembangunan dalam berbagai bidang.

Program jaminan kesehatan masyarakat ini diterapkan bagi seluruh penduduk Kota Batam dan tidak dipungut biaya apapun dari mereka. Ini ditujukan untuk membantu pelayanan kesehatan masyarakat bagi semua lapisan. Dengan adanya masyarakatyang terlalu banyak maka masyarakat sulit untuk mendapatkan pelayanan kesehatan. Pemerintah membuat program Jamkesmas juga bertujuan agar masyarakat dapat mendapatkan pelayanan dengan lebih mudah dan lebih baik serta tidak dipungut biaya. Kementerian Kesehatan 
memberikan kuota Jaminan Kesehatan Masyarakat (Jamkesmas) di Kota Batam sebagai berikut yang akan di uraikan dalam Tabel 1.

Tabel 1

Jumlah Kuota dan Anggaran Jaminan Kesehatan Masyarakat

\begin{tabular}{cccc}
\hline NO & TAHUN & JUMLAH WARGA KURANG MAMPU & ANGGARAN \\
\hline 1 & 2012 & 136.044 & 6.000 .000 .000 \\
2 & 2013 & 157.850 & 16.000 .000 .000 \\
\hline
\end{tabular}

Sumber: Profil Puskesmas Sekupang Tahun 2013

Pada tahun 2013 Pemerintah Kota Batam mewajibkan setiap masyarakat yang berobat ke Puskesmas membayar retribusi Rp 5 ribu, kecuali mereka memegang kartu Jamkesmasperaturan tersebut diterapkan karena pada tahun-tahun sebelumnya banyak warga yang tergolong mampu juga mendapatkan pengobatan gratis.Ini dilakukan agar program kesehatan gratis tepat sasaran dan dinikmati warga kurang mampu. Karena selama ini banyak warga yang tergolong mampu namun juga memanfaatkan program pengobatan gratisdan bagi masyarakat yang telah dilayani Jamkesmas, secara otomatis tidak lagi dilayani pada program kesehatan yang lain. Masyarakat dikatakan mampu apabila memiliki luas lantai bangunan tempat tinggal lebih dari $8 \mathrm{~m} 2$ per orang, Jenis lantai tempat tinggal terbuat dari tanah, kayu berkualitas, dan tembok diplester. Sumber penerangan rumah tangga menggunakan listrik dan sumber air minum berasal dari sumber mata air terlindung dan sanggup membayar biaya pengobatan di puskesmas.

Pelayanan disediakan pada berbagai lembaga institusi pemerintah dengan aparat sebagai pemberi pelayanan secara langsung kepada masyarakat. Kehidupan masyarakat yang semakin kompleks menuntut adanya suatu pelayanan yang semakin berkualitas, yang mana dalam hal ini pemerintah sebagai penyedia harus lebih intensif didalam memperhatikan pelayanan tersebut karena diberbagai kesempatan pemerintah senantiasa menjanjikan pelayanan yang memuaskan kepada masyarakat Berangkat dari kesadaran tersebut, pemerintahan di Indonesia selalu berupaya untuk memberikan yang terbaik kepada rakyat Indonesia, termasuk dengan membuat regulasi kebijakan mengenai jaminan kesehatan bagirakyat Indonesia, Karena sehat adalah suatu keadaan sejahtera sempurna, maka luas masalah kesehatan bukanlah seluas suatu bidang sederhana dan sempit.Kesehatan dapat mencakup masalah fisik, mental, dan sosial serta tidak hanya keadaan yang bebas dari penyakit cacat dan kelemahan. Mengingat bahwa sebuah negara akan bisa menjalankan pembangunan yang baik apabila didukung oleh masyarakat yang sehat secara jasmani dan 
rohani. Masalah kesehatan nasional sampai saat ini masih cukup tinggi dilihat dari indikator keberhasilan secara umum, status kesehatan tersebut akan lebih buruk pada kelompok masyarakat miskin.

Hal tersebut karena keterbatasan pengetahuan, akses pelayanan kesehatan dan kemampuan membayar pelayanan kesehatan yang semakin mahal. Untuk menjamin akses penduduk miskin terhadap pelayanan kesehatan, Pemerintah telah menyelenggarakan program Jaminan Kesehatan Masyarakat (Jamkesmas). Dengan Jamkesmas diharapkan keterbatasan akses terhadap pelayanan kesehatan bagi masyarakat miskin dan tidak mampu dapat diatasi.Peraturan Menteri Kesehatan Republik Indonesia Nomor 2581/MENKES/PER/XII/2011 tentang Petunjuk Teknis Pelayanan Kesehatan Dasar Jaminan Kesehatan MasyarakatPasal 1 Pengaturan Pedoman Pelaksanaan Program Jaminan Kesehatan Masyarakat bertujuan untuk memberikan acuan bagi Pemerintah Pusat, Pemerintah Daerah Provinsi, Pemerintah Daerah Kabupaten/Kota dan pihak terkait penyelenggaraan program Jaminan Kesehatan Masyarakat (Jamkesmas) dalam rangka memberikan kemudahan dan akses pelayanan kesehatan kepada peserta di seluruh jaringan fasilitas kesehatan Jamkesmas, mendorong peningkatan pelayanan kesehatan yang terstandar bagi peserta, tidak berlebihan sehingga terkendali mutu dan biayanya, dan terselenggaranya pengelolaan keuangan yang transparan dan akuntabel.

Pasal 2 Penyelenggaraan Program Jaminan Kesehatan Masyarakat sebagaimana dimaksud dalam Pasal 1 mengacu pada prinsip-prinsip dana amanatdengan pemanfaatan untuk semata-mata peningkatan derajat kesehatan masyarakat miskin, menyeluruh (komprehensif) sesuai dengan standar pelayanan medik yang cost effective dan rasional, pelayanan terstruktur, berjenjang dengan portabilitas dan ekuitas, efisien, transparan dan akuntabel.

Jaminan Kesehatan Masyarakat untuk wilayah Kota Batam dalam pelaksanaannya masyarakat miskin yang sudah terdata oleh Pemerintah akan mendapatkan kartu Jamkesmas yang dapat digunakan di Puskesmas atau rumah sakit yang telah di tunjuk oleh Pemerintah. Jaminan Kesehatan Masyarakat (Jamkesmas) diambil dari Anggaran Pendapatan Belanja Negara (APBN) yang diberikan pemerintah Provinsi Kepulauan Riau.Surat Keterangan Miskin merupakan salah satu syarat mutlak yang harus dipenuhi oleh pasien untuk mendapatkan pelayanan Jamkesmas. Jamkesmas lebih meluas cakupannya, karena meliputi seluruh warga yang belum memiliki kartu jaminan atau kartu asuransi kesehatan apapun. 
Program ini hanya dikhususkan untuk beberapa rumah sakit non-swasta. Pada pelaksanaannya di Kota Batam, program ini masih belum banyak diketahui masyarakat miskin sehingga masih banyak ditemui masyarakat miskin yang enggan berobat ke Puskesmas atau Rumah Sakit. Beberapa dari warga kota Batam masih merasa asing mendengar adanya program Jamkesmas. Bahkan terdapat adanya kesalahan dalam pendataan warga dapat memungkinkan program ini tidak tersalurkan merata bagi masyarakat dengan tingkat ekonomi rendah.

Tidak sedikit pula program Jamkesmas ini menuai pro dan kontra mengenai sasaran kebijakan tersebut dalam klasifikasi masyarakat yang diberi bantuan, terbukti dengan keresahan yang timbul di tengah-tengah masyarakat yang dalam perjalanan proses program pelayanan ini tidak begitu adil dirasakanbagi masyarakat, sebab warga yang termasuk dalam taraf ekonomi tinggi pun dapat mengakses pelayanan program ini. Apabila program sudah baik, tapi masih banyak masyarakat yang belum paham, maka perjalanan program itu menjadi kurang dirasakan masyarakat miskin.

Berdasarkan persoalan-persoalan yang dikemukakan diatas, maka sekiranya masih perlu dikaji ulang perihal pengimplementasian program Jamkesmas ini. Permasalahanpermasalahan tersebut mengakibatkan pelayanan di puskesmas dan rumah sakit-rumah sakit kota Batam kurang efektif. Salah satunya utang pemerintah kota batam dengan rumah sakit otorita batam sebesar 1 milyar rupiah terkait dengan pembiayaan program jaminan kesehatan masyarakat, dengan adanya masalah ini rumah sakit otorita batam menolak menerima masyarakat miskin untuk berobat di rumah sakit otorita batam dan meminta pemerintah kota Batam segera menulaskan utang tersebut agar program jaminan kesehatan masyarakat bisa berjalan kembali di rumah sakit otorita batam.

Sesuai dengan permasalahan diatas dalam pelaksanaan Program Jaminan Kesehatan Masyarakat (Jamkesmas) yang telah dijelaskan khususnya untuk wilayah kota Batam maka perlu dilakukan pengkajian ulang terhadap implementasi program pelayanan kesehatan khususnya Jaminan Kesehatan Masyarakat di Kota Batam.Sesuai dengan tujuan Jaminan Kesehatan Masyarakat menurut Dinas Kesehatan yaitu Meningkatkan askes dan mutu pelayanan kesehatan terhadap seluruh masyarakat miskin dan tidak mampu agar tercapai derajat kesehatan masyarakat yang optimal secara efektif dan efisien. Dengan tujuan khusus untuk meningkatkan cakupan masyarakat miskin dan tidak mampu yang mendapat pelayanan kesehatan di Puskesmas serta jaringannya dan di Rumah Sakit, lalu untuk meningkatkan 
kualitas pelayanan kesehatan bagi masyarakat miskin serta terselenggaranya pengelolaan keuangan yang transparan.

Sesuai masalah-masalah dalam pelaksanaan Program Jaminan Kesehatan Masyarakat yang telah di jelaskan diatas khususnya dalam wilayah Kota Batam. Dan juga, dalam hal ini peneliti tertarik untuk meneliti bagaimana Implementasi Program Jaminan Kesehatan Masyarakat (Jamkesmas) di Puskesmas sekupang, dimana Puskesmas Sekupang merupakan Puskesmas yang kekurangan tenaga medis karena bisa dilihat dariJumlah Penduduk di wilayah kerja Puskesmas Sekupang Kota Batam sampai akhir Tahun 2013 yaitu 92.806 Jiwa dan pada akhir Tahun 2016 sebanyak 74.877 Jiwa.

\section{METODOLOGI}

Jenis penelitian yang digunakan adalah Kualitatif. Penelitian kualitatif adalah penelitian yang menekankan pada pemahaman megenai masalah-masalah dalam kehidupan sosial berdasarkan kondisi realitas atau natural setting yang holistis, kompleks dan rinci. Penelitian kualitatif adalah penelitian tentang riset yang bersifat deskriptif dan cenderung menggunakan analisis. Lokasi Penelitiandilaksanakan Puskesmas Sekupang Kota Batam Tahun 2017. Alamat: J1.Raja Haji No. 6 Batam, Kepulauan Riau. No Telp: 0778-325-517. Sumber Data meliputi Data primer adalah data yang di peroleh melalui wawancara. Meliputi pembicaraan dengan pihak-pihak yang berhubungan dengan penemuan secara langsung, dengan cara pengalaman dan pencatatan sistematik sebagai fenomena yang muncul. Data sekunder adalah data yang di peroleh dari bahan-bahan yang di perlukan seperti, dokumentasi dengan cara menghimpun sumber-sumber yang ada. Sumber data sekunder yang di perlukan antara lain produk-produk hukum nasional, peraturan daerah, serta bahan pustaka.

Teknik Pengumpulan Data meliputi Observasi adalah suatu kegiatan mendapatkan informasi yang diperlukan untuk menyajikan gambaran riil suatu peristiwaatau kejadian untuk menjawab pertanyaan penelitian, untuk membantu mengerti perilaku manusia, dan untuk evaluasi yaitu melakukan pengukuran terhadap aspek tertentu melakukan umpan balik terhadap pengukuran tersebut. Wawancara adalah tanya jawab untuk memperoleh informasi atau keterangan akan suatu hal dan wawancara merupakan teknik pengumpulan data yang diperoleh secara langsung antara pewawancara dengan narasumber. Dokumentasi adalah Kumpulan dari dokumen-dokumen dapat memberikan keterangan atau bukti yang berkaitan dengan proses pengumpulan dan pengelolaan dokumen secara sistematis serta menyebar 
luaskan kepada pemakai informasi tersebut. Teknik Pemilihan Informan, Informan Penelitian deskriptif kualitatif tidak dimaksudkan untuk membuat generalisasi dari hasil penelitiannya.

Oleh karena itu, pada penelitian kualitatif tidak dikenal adanya populasi dan sampel. Subjek penelitian yang telah tercermin dalam fokus penelitian ditentukan secara sengaja. Subjek penelitian ini menjadi informan yang akan memberikan berbagai informasi yang diperlukan selama proses penelitian, informan penelitian ini meliputi beberapa macam seperti meliputi informan kunci, yaitu mereka yang mengetahui dan memiliki berbagai informasi pokok yang diperlukan dalam penelitian. informan utama, yaitu mereka yang terlibat langsung dalam interaksi sosial yang diteliti. informan tambahan, yaitu mereka yang dapat memberikan informasi walaupun tidak langsung terlibat dalam interaksi sosial yang diteliti.Teknik Analisis Data meliputi Reduksi data merupakan proses pengumpulan data penelitian, seorang peneliti dapat menemukan kapan saja waktu untuk mendapatkan data yang banyak, apabila peneliti mampu menerapkan metode observasi, wawancara atau dari berbagai dokumen yang berhubungan dengan subjek yang di teliti.

Penyajian data yang diperoleh dikategorikan menurut pokok permasalahan dan dibuat dalam bentuk yang sederhana sehingga memudahkan peneliti untuk melihat pola-pola hubungan satu data dengan data lainnya. Mengambil kesimpulan dan verifikasiKegiatan penyimpulan merupakan langkah lebih lanjut dari kegiatan reduksi dan penyajian data. Data yang sudah direduksi dan disajikan secara sistematis akan disimpulkan sementara. Kesimpulan yang diperoleh pada tahap awal biasanya kurang jelas, tetapi pada tahap-tahap selanjutnya akan semakin tegas dan memiliki dasar yang kuat. Kesimpulan sementara perlu dilakukan verifikasi.

\section{PEMBAHASAN}

Konsep Implementasi Menurut Donald S. Van Meter dan Carl E. Van Horn ada enam variabel yang mempengaruhi kinerja implementasi, yakni: standar dan sasaran kebijakan, sumberdaya, komunikasi antar organisasi dan penguatan aktivitas, karakteristik agen pelaksana, disposisi implementor, dan kondisi sosial, ekonomi dan politik. Maka implementasi peraturan menteri kesehatan RI Nomor 2581/menkes/PER/XII/2011 tentang petunjuk teknis pelayanan kesehatan dasar jaminan kesehatan masyarakat di puskesmas sekupang kota Batam tahun 2013 harus mengetahui implementasi kebijakan dengan mengacu kepada elemen-elemen pokok impelentasi kebijakan, yaitu sebagai berikut. standar dan 
sasaran kebijakan yaotu Kepala UPT Puskesmas Sekupang Kota Batam senantiasa memberikan penjelasan mengenai tugas pokok dan fungsi kepada petugas pelaksana kebijakan tentang standard atau target yang harus direalisasikan.

Dengan penjelasan mengenai standar atau ukuran-ukuran dasar serta tujuan-tujuan kebijakan diharapkan para pelaksana kebijakan mengerti dan memahami arti dan tujuan dari sebuah kebijakan yang dilaksanakan. bahwa untuk mengoptimalkan pengelolaan Pelayanan Jaminan Kesehatan Masyarakat, pihak Dinas Kesehatan Kota Batam telah memberikan pelatihan terkait dengan Petunjuk Teknis dan petunjuk pelaksanaan Pelayanan Kesehatan Dasar Jaminan Kesehatan Masyarakat. Hal tersebut dilakukan untuk mmeberikan pemahaman-pemahaman yang mendalam terhadap para pegawai untuk dapat merealisasikan akan tujuan ukuran-ukuran dasar dalam pencapai tujuan pelaksanaan kebijakan. diketahui bahwa selaku bagian Kepala Bagian Tata Usaha Puskesmas Sekupang Kota Batam senantiasa melakukan pembenahan sumber-sumber baik sarana dan prasarana Puskesmas Sekupang untuk memperlancar suatu pekerjaan.

Pembenahan tersebut di sesuaikan dengan anggaran dana yang ada untuk lebih meningkatkan kualitas pelayanan jaminan kesehatan masyarakat di Puskesmas Sekupang Kota Batam. Sumber Daya yaitu diketahui bahwa pegawai puskesmas masih kurang, apalagi tenaga medis dan pegawai dibagian pelayanannya seharusnya pihak puskesmas menambah pegawai lagi supaya bisa melayani masyarakat dengan semestinya. diketahui bahwa implementasi kebijakan perlu dukungan sumber daya baik dari sumber daya (human resources) maupun sumber daya non-manusia (non human resources). Secara jujur kami katakan bahwa sumber daya manusia yang dimiliki khususnya di Puskesmas Sekupang ini masih terbatas. Seperti kurangnya tenaga medis karena bisa dilihat dari jumlah penduduk di wilayah kerja Puskesmas Sekupang Kota Batam yang lumayan padat. Namun dengan demikian kami tetap berupaya semaksimal mungkin untuk memberikan pelayanan yang maksimal terhadap masyarakat yang menggunakan pelayanan kesehatan masyarakat di Puskesmas Sekupang ini. Untuk memaksimalkan pelayanan jaminan kesehatan masyarakat di Puskesmas Sekupang, Pemerintah Kota Batam melalui Dinas Kesehatan Kota Batam menambah tenaga medis, langkah ini ditempuh untuk mengatasi permasalahan pelayanan jaminan kesehatan masyarakat. Sumber daya non-manusia (non human resources), secara umum sarana prasarana adalah alat penunjang keberhasilan suatu proses upaya yang dilakukan di dalam pelayanan publik, karena apabila kedua hal ini tidak tersedia maka semua 
kegiatan yang dilakukan tidak akan dapat mencapai hasil yang diharapkan sesuai dengan rencana.

Kondisi sarana dan prasarana di Puskesmas Sekupang masih kurang untuk mencapai target derajat kesehatan masyarakat yang setinggi-tingginya mulai dari ruang untuk mendapatkan pengobatan dan peralatan medis dan sarana penunjang lainnya. Hubungan antar organisasi diketahui bahwa pihak Puskesmas Sekupang Kota Batam bekerja sama dengan Dinas Kesehatan Kota Batam dalam rangka memsosialisasikan kebijakan-kebijakan dimaksud untuk memberikan pemahaman kepada masyarakat yang menggunakan pelayanan kesehatan untuk sadar arti pentingnya kesehatan dengan tujuan demi kesejahteraan bersama.salah satu tujuan dari lintas organisasi tersebut adalah membangun pola kemitraan agar tujuan dari masing-masing lembaga dapat terwujud sesuai dengan tujuan yang telah ditetapkan. diketahui bahwa masyarakat miskin yang mendapatkan pelayanan di Puskesmas Sekupang telah di data oleh Dinas Sosial dan Pemakaman Kota Batam sudah ada karakteristik masyarakat yang berhak menerima pelayanan jaminan kesehatan masyarakat seperti masyarakat yang tidak mampu membayar biaya pengobatan dan untuk gelandangan, anak terlantar, pengemis apabila tidak terdaftar oleh surat keputusan menteri kesehatan ini akan di proses oleh Dinas Sosial dan Pemakaman untuk bisa mendapatkan pelayanan jaminan kesehatan masyarakat.

Karakteristik Agen Pelaksana diketahui bahwa masyarakar kurang puas terhadap pelayanan yang diberikan oleh pegawai puskesmas, padahal bersikap ramah tamah sudah menjadi kewajiban dalam memberikan pelayanan kepada masyarakat. diketahui bahwa masyarakar kurang puas terhadap pelayanan yang diberikan oleh pegawai puskesmas, padahal bersikap ramah tamah sudah menjadi kewajiban dalam memberikan pelayanan kepada masyarakat. Kondisi Sosial, Ekonomi dan Politik diketahui bahwa kondisi ekonomi, dengan tidak stabilnya kebutuhan harga pokok yang terjadi maka akan sangat menyulitkan masyarakat untuk memenuhi kebutuhannya sehari-hari termasuk juga untuk mendapatkan makanan yang layak dikonsumsi setiap harinya. diketahui untuk mendapatkan makanan dalam sehari saja sangat sulit, apalagi untuk berobat pasti banyak biayanya tidak hanya sekedar kenyang makanan yang layak di konsumsi juga harus didapatkan demi kesehatan masyarakat. diketahui bantuan jaminan kesehatan masyarakat ini sangat dibutuhkan oleh masyarakat miskin dan harapannya supaya anggaran yang diterima oleh pemerintah diberikan kepada masyarakat yang benar-benar membutuhkan. 
Disposisi implementator mencakup tiga hal penting, yaitu respon implementor terhadap kebijakan, yang akan mempengaruhi kemauannya untuk melaksanakan kebijakan, kognisi, yaitu pemahaman tehadap kebijakan, intensitas disposisi implementor, yaitu preferensi nilai yang dimiliki oleh implementor. diketahui bahwa dalam mengimplementasikan kebijakan dalam upaya meningkatkan pelayanan kesehatan masyarakat di Puskesmas Sekupang adalah menumbuhkan komitmen dan semangat yang tinggi dari pelaksana kebijakan dalam melaksanakan tugas, wewenang, fungsi, dan tanggung jawab sesuai dengan peraturan yang telah ditetapkan. diketahui bahwa Disposisi implementor dipengaruhi oleh sikap dari pelaksana kebijakan dalam melaksankan tugas. Apabila implementator memiliki sikap yang baik maka dia akan dapat menjalankan kebijakan dengan baik seperti apa yang diinginkan oleh pembuat kebijakan, sebaliknya apabila sikapnya tidak mendukung maka implementasi tidak akan terlaksana dengan baik. diketahui bahwa dalam menerima kebijaksanaan yang telah dikeluarkan oleh pemerintah khususnya dalam pelayanan perlu mendapatkan dukungan dari seluruh lapisan masyarakat.

Masyarakat dituntut dapat memahami, menghayati, dan melaksanakannya sebagaimana yang diharapkan. Dengan kata lain, keterlibatan atau partisipasi masyarakat sangat dibutuhkan demi terwujudnya pelayanan kesehatan masyarakat di Puskesmas Sekupang Kota Batam. diketahui bahwa partisipasi masyarakat diharapkan dapat membantu dalam mendukung peningkatan kualitas pelayanan dan keterlibatan yang benar-benar dirasakan, yang timbul dari hati atau perasaan seseorang sebagai kepentingan bersama keterlibatan masyarakat sangat membantu dalam melihat bagaimana kinerja pegawai dalam memberikan pelayanan kepada masayarakat. diketahui bahwa dalam memberikan pelayanan, pegawai puskesmas terkadang tidak memberikan pelayanan yang baik seperti memberikan informasi tentang bagaimana prosedur untuk mendapatkan pelayanan kesehatan di Puskesmas Sekupang. Selain itu, ketika menanyakan informasi tentang perbedaan data diri pasien dengan data jamkesmas, pegawai puskesmas kurang bersikap ramah tamah ketika memberikan informasi kepada masyarakat.

\section{KESIMPULAN}

Secara umum implementasi peraturan menteri kesehatan RI Nomor 2581/menkes/PER/XII/2011 tentang petunjuk teknis pelayanan kesehatan dasar jaminan kesehatan masyarakat harus diarahkan guna pencapaian kondisi yang kondusif bagi seluruh aspek kehidupan masyarakat Kota Batam dan khususnya dalam kawasan Puskesmas 
Sekupang tentang pelayanan jaminan kesehatan masyarakat perlu disesuaikan dan diatur sesuai dengan perkembangannya, dan kebutuhan masyarakat.

Standard dan Sasaran Kebijakan, Kepala UPT Puskesmas Sekupang Kota Batam senantiasa selalu memberikan penjelasan mengenai tugas pokok dan fungsi kepada setiap petugas pelaksana kebijakan tentang standard atau target yang harus direalisasikan. Dengan penjelasan mengenai standar atau ukuran-ukuran dasar serta tujuan-tujuan kebijakan diharapkan para pelaksana kebijakan mengerti dan memahami arti dan tujuan dari sebuah kebijakan yang dilaksanakan.Sumber daya, Keterbatasan sumber daya yang dimiliki Puskesmas Sekupang Kota Batam berpengaruh terhadap Implementasi Peraturan Menteri Kesehatan RI Nomor 2581/MENKES/XII/2011 tentang Petunjuk Teknis Pelayanan Kesehatan Dasar Jaminan Kesehatan Masyarakat dimana sumber daya manusia yang dimiliki khususnya di Puskesmas Sekupang ini masih terbatas. Seperti kurangnya tenaga yang menerima pelayanan dan kurangnya tenaga medis karena bisa dilihat dari jumlah penduduk di wilayah kerja Puskesmas Sekupang Kota Batam yang lumayan padat dan jika dilihat dari Sumber daya non-manusia (non human resources), yaitu mencakup sarana dan prasarana masih kurang mendukung padahal sarana dan prasana adalah alat penunjang keberhasilan suatu proses upaya yang dilakukan di dalam pelayanan publik.Hubungan antar organisasi,

Dalam memaksimalkan pelayanan dari sektor kesehatan pihak Puskesmas Sekupang Kota Batam bekerja sama dengan Dinas Kesehatan Kota Batam dalam rangka mensosialisasikan kebijakan-kebijakan dimaksudkan untuk memberikan pemahaman kepada masyarakat yang menggunakan pelayanan kesehatan untuk sadar arti pentingnya kesehatan dengan tujuan demi kesejahteraan kita sendiri, kemudian Puskesmas Sekupang bekerjasama dengan Dinas Sosial dan Pemakaman Kota Batam untuk menerima data masyarakat yang berhak menerima pelayanan jaminan kesehatan masyarakat.Karakteristik agen pelaksana, Salah satu kendala yang dihadapi dalam melayani masyarakat harus dengan sepenuh hati tapi terkadang apa yang dipikirkan tidak sesuai dengan kenyataan seperti ada kesalahan nama dikartu jaminan kesehatan masyarakat dan itu tidak bisa kita memberikan pelayanan harus diubah terlebih dahulu tetapi masyarakat tetap ingin diberikan pelayanan dan namanya juga manusiawi jadi terpancing emosi saya dalam melayani masyarakat dan sudah pasti di stigma oleh masyarakat.Kondisi sosial, ekonomi, dan politik, Kondisi yang terjadi di masyarakat menjadi faktor yang berpengaruh terhadap keberhasilan pelaksanaan peraturan menteri kesehatan RI Nomor 2581/menkes/PER/XII/2011 tentang petunjuk teknis pelayanan 
kesehatan dasar jaminan kesehatan masyarakat dimana banyak harapan masyarakat kepada pemerintah untuk berusaha supaya anggaran kesehatan masyarakat selalu bertambah dan tepat sasaran memberikan bantuan kepada masyarakat.Disposisi implementor,Dalam menjalankan kebijakan para implementor harus berusaha meningkatkan pelayanan dalam bentuk menumbuhkan komitmen dan semangat kerja yang tinggi dalam melaksanakan tugas, wewenang, fungsi, dan tanggung jawab sesuai dengan peraturan yang telah ditetapkan. Untuk meningkatkan pelayanan keterlibatan sangat membantu dalam melihat kinerja pegawai saat menjalankan kebijakan.

Saran-saran yaitu Dalam rangka mengoptimalkan peraturan menteri kesehatan RI Nomor 2581/menkes/PER/XII/2011 tentang petunjuk teknis pelayanan kesehatan dasar jaminan kesehatan masyarakat maka disarankan agar meningkatkan pelayanan terhadap masyarakat dan menambah pegawai untuk bisa memberikan pelayanan yang berkualitas. Kepada para koordinator yang bertanggung jawab, sebaiknya melihat secara langsung bagaimana para pegawai memberikan pelayanan kesehatan kepada masyarakat sehingga masyarakat bisa mendapatkan kenyamanan saat berada di Puskesmas Sekupang.Untuk para elit politik khususnya untuk pemimpin Kota Batam, sebaiknya melihat jalannya programprogram yang akan diberikan kepada masyarakat miskin khususnya program jaminan kesehatan masyarakat sudah tepat sasaran atau belum, kemudian mengontrol jalannya anggaran dan memberikan jaminan bahwa anggaran kesehatan untuk masyarakat miskin akan terus ada dan bertambah anggarannya di setiap tahun.

\section{REFERENSI}

Agustino, Leo. 2006. Politik dan Kebijakan Publik. Bandung: AIPI.

AG, Subarsono. 2007. Analisa Kebijakan Publik Konsep, Teori, dan Aplikasi. Yogyakarta: Pustaka Pelajar.

Irwan. 2015. Dinamika dan Perubahan Sosial pada Komunitas Lokal. Yogyakarta: Deepublish.

Mulyadi, Deddy. 2015. Studi Kebijakan Publik dan Pelayanan Publik. Bandung: Alfabeta.

Moleong, Lexy J. 2009. Metode Penelitian Kualitatif. Bandung: PT. Remaja Rosdakarya. Nugroho, Riant. 2006. Kebijakan Publik untuk Negara-negara Berkembang. Jakarta: PT. Elex Media Komputindo. 
Purwoastuti, Endang., dan Elisabeth Siwi. 2015. Ilmu Kesehatan Masyarakat dalam Kebidanan. Yogyakarta: Pustaka Baru Press.

Solihin, Wahab.2007.Analisis Kebijaksanaan dari Formulasi ke Implementasi. Bandung: Bumi Aksara.

Sudarma, Momon. 2008. Sosiologi Kesehatan. Jakarta: Salemba Medika.

Soekarwo, 2003. Berbagai Permasalahan Keuangan Daerah. Jakarta: Rajawali Pres.

Sujarweni, Wiratna.2014.Metodologi Penelitian. Yogyakarta: Pustaka Baru Press.

Sugiyono, 2014. Metode Penelitian Kualitatif Kuantitatif dan R\&D. Bandung.

Winarno, Budi.2007. Kebijakan Publik Teori dan Proses .Yogyakarta: Medpress.

.2014. Kebijakan Publik Era Globalisasi .Yogyakarta: Caps.

\section{Website :}

http://skpd.batamkota.go.id/kesehatan/files/2015/05/Profile-dinkes-2014-pdf-1.pdf

http://www.academia.edu/10123441/BAB_III_PENDEKATAN_DAN_TEORI_TEORI_IMPLEMENTAS

I_KEBIJAKAN_PUBLIK

http://www.antarakepri.com/berita/23508/pemkot-batam-segera-bagikan-157850-kartu-

jamkesmas.

http://nasional.inilah.com/read/detail/1772447/pemkot-bayar-utang-ke-rs-otorita-batam.

\section{Dokumen:}

Departemen Kesehatan Tahun 2006.

Keputusan Menteri Kesehatan No.128 tahun 2004.

Peraturan Menteri Kesehatan Republik Indonesia nomor 2581/MENKES/PER/XII/2011 tentang Petunjuk Teknis Pelayanan Kesehatan Dasar Jaminan Kesehatan Masyarakat.

Peraturan Menteri Kesehatan Republik Indonesia Nomor 75 Tahun 2014 tentang Pusat Kesehatan Masyarakat.

Peraturan Menteri Kesehatan Nomor 903/MENKES/PER/V/2011 tentang Pedoman Pelaksanaan Program Jaminan Kesehatan Masyarakat.

Profil Dinas Kesehatan Batam, lihat http://skpd.batamkota.go.id/kesehatan/files/2015/05/Profile-dinkes-2014-pdf-1.pdf.

Profil Puskesmas Sekupang Tahun 2013.

Profil Dinas Sosial dan Pemakaman Kota Batam tahun 2014.

Undang-Undang Nomor 36 Tahun 2009 tentang Kesehatan. 